Session 1547

\title{
Senior EET Design Projects to Aid Individuals with Disabilities
}

\author{
Henry G. Ansell \\ Penn State Berks-Lehigh Valley College
}

\begin{abstract}
There are engineering programs throughout the U.S. that offer senior design courses involving projects to aid individuals with disabilities, but technology programs that do this are rarer. This paper discusses experience with technology students doing successful client-based senior design projects to aid individuals with disabilities. It explains how projects were chosen and how funding was obtained.
\end{abstract}

\section{Introduction}

During the fall 1996 semester at Penn State Berks Campus (now part of Penn State Berks-Lehigh Valley College) preparations were made for a technology senior design project course scheduled for the following semester. The students were in the Berks Campus evening BS EET Program (extended from Penn State Harrisburg).

This program had run at Penn State Berks Campus several years earlier, and students at that time had considerable latitude in writing specifications for their projects. At that earlier time there had been two sections, each involving a different instructor, including this author. In some cases the students made an effort but did not achieve a prototype; in other cases a device was made but was not sufficiently advanced to be really useful to anyone.

For the 1996-1997 academic year, this author wanted to have the students do a design that was client-based in order to provide a more realistic experience for students. It was announced to the students that each senior design project was to be a device to aid an individual with a disability. A satisfactory working prototype was to be made and delivered to an individual for his or her use.

The literature includes reports of engineering students, sometimes in collaboration with others, doing design projects to aid individuals with disabilities ${ }^{1-7}$. This instructor felt that baccalaureate technology students could also successfully do senior design projects to help people with disabilities.

\section{Team Formation}

Teams for the project were formed in fall 1996. When this program was given previously at Berks Campus, the design teams typically had two people per team, and in some cases only one person. However, in fall 1996, in order to have a greater probability of the success of the projects, this instructor decided to have four persons per team. There were twelve students in the class, and this instructor, who was also coordinator of the BS EET program at Berks Campus, decided that there would be one section of projects with three teams of four students per team. 
When students are left to form teams entirely on their own, they often form on the basis of friendships, and it sometimes happens that the most able students join together to form one team, while the least able students find themselves together on a remaining team. Such an occurrence would give one team a reduced chance of completing the project successfully.

For better balance, this instructor chose the top three students, based on grades, to be team captains for the teams that would be formed. The team captains were asked to alternately draft students to their teams.

\section{Choosing Projects}

The work of choosing projects was mainly done during the fall 1996 semester, before the start of the spring 1997 senior design project course.

To begin, this instructor used a book of 1993 engineering senior design projects to aid people with disabilities ${ }^{1}$, projects sponsored by the National Science Foundation. He eliminated projects that lacked any electrical or electronic aspect, and gave the students 39 project summaries. Using this list, each student was asked to tentatively select a specific project.

From the students' responses, this instructor formed a list of sample projects that could be given to therapists, to illustrate the sort of projects that the class was interested in doing.

Therapists at a rehabilitation facility in our county, Reading Rehabilitation Hospital, provided an important source of ideas for projects that could be useful to clients in the community. Two separate one-hour brainstorming sessions were conducted at the rehab facility, with different therapists meeting students from the class at each session. The discussions at these brainstorming sessions provided a large number of possible topics for the students to consider.

This instructor consulted by phone, on several occasions, with the rehabilitation counselor at United Cerebral Palsy of Bethlehem, and she suggested several useful possibilities for student projects for her clients. These ideas were given to the students.

This instructor also visited the local branch of Easter Seals, in Reading, and spoke to therapists there who made some valuable suggestions concerning possible student projects. These ideas were also given to the students.

From all of the ideas suggested by therapists and rehabilitation counselors in the community, each student team was asked to pick four projects. The teams were asked to submit proposals, including an estimate of how much money was needed for parts for each project.

The final choice of projects depended on obtaining funding for projects. From the students' choices, this instructor compiled a list of ten proposed student projects, with brief descriptions and cost estimates, to be used in obtaining funds for the projects. 


\section{Funding}

The list of ten proposed student projects was submitted to the rehab facility, seeking possible funding from them. Reading Rehabilitation Hospital chose to fund a keyless entry system. This provided a project for the first team.

Funding support came from another source. This author had helped to found a group in our county, the Assistive Technology Committee, that is concerned with advancing assistive technology in our county. The students' proposed projects were presented to this committee, and they were discussed. One of the projects, an alarm for an untended stove, received a warm reception from a member of the committee, who was and is a rehabilitation counselor for the Office of Vocational Rehabilitation (OVR). He was willing to have OVR fund the project for a client of OVR. This provided a project for a second team.

Finally, a phone call was received from the rehabilitation counselor from United Cerebral Palsy of Bethlehem, informing this instructor of a new idea for a project which she had in mind for one of her clients that was willing and able to pay for it. This was the adaptation of an electric car for a four-year old boy with cerebral palsy. The third team was asked if they would be willing to do this project, and they agreed. Ultimately, this was funded by GPU, an electric company, the employer of one of the students on this third team.

After external sponsorship was received, there was also funding received from Penn State University. This was available for partially funding any or all of the projects.

\section{Summary of the Projects}

One team of students designed and built a keyless entry system. This allowed a severely disabled client of Reading Rehabilitation Hospital to unlatch her front door for a few seconds by tapping a code on her portable telephone. Therapists at the rehab facility had said that many patients are so severely disabled, and find it so troublesome to get to the door to let someone in, that they leave their door open continually. The rehab facility designated the client for this device.

Another team of students designed and built an alarm system to alert a user that her electric stove is untended. The Office of Vocational Rehabilitation funded this project for a client that they designated. OVR was particularly concerned about the risk of fires from untended stoves. There are many aging people who have become forgetful, and need a reminder when their stove is untended. A provisional patent has been filed, and a manufacturer is being sought for this device.

A third team of students adapted an electric car for a four-year-old boy with cerebral palsy. A "jelly-bean" switch was installed in the car, which the boy presses to move forward. The parents do the steering by remote control, and also have an override allowing them to prevent the switch in the car from operating. After completion of the device, the students expressed an interest in commercializing it. 


\section{Delivery of the Devices}

Before possession of the devices was given to the clients, clients signed liability waivers assuming full responsibility for any problems or losses due to their use or reliance on the devices.

The keyless entry system and the untended stove alarm were installed by students in the homes of the clients. Videos of the installation were made, parts of which were shown at a student presentation at the end of the semester. The adapted electric car was given to the parents of the boy with cerebral palsy at the student presentation.

\section{The Students' Experience}

This design experience imposed considerably more pressure on the students than if they had chosen projects that were not client-based. The designs had to be suitable for the clients. The final product had to work properly after being delivered (and installed, for two of the projects). There was also the pressure of time because the projects had to be completed before the end of the semester.

At the end of the semester the students gave a presentation and friends and family were invited. This was a means of providing additional satisfaction to the students, as well as another opportunity to develop their communication skills.

\section{Conclusion}

Many engineering colleges include senior student projects to aid individuals with disabilities. However, it is more difficult to find technology programs doing this. This instructor has found that for their senior project courses, baccalaureate technology students can also successfully design and implement projects very useful to people with disabilities.

Engineering colleges around the U.S. have taken advantage of the National Science Foundation's BRAD program that supports senior engineering design projects to aid individuals with disabilities ${ }^{8}$. The NSF may also be willing to support such projects in technology programs. In any case, community funding may be obtainable to do such projects, from a rehabilitation facility, from the Office of Vocational Rehabilitation, from individuals who would receive the devices, from employers of the students working on the projects, and from the university itself.

Suggestions for possible projects can be obtained from therapists and rehabilitation counselor in the community, especially by having a brainstorming session with the students and the therapists.

The students can gain valuable realistic experience from client-based design. The pressures on the students are strong, but they gain from this realism. Upon the successful completion of a client-based project to help someone with a disability, a student also gains a feeling of accomplishment for having designed a product that is needed and used by someone. 


\section{References}

1. National Science Foundation 1993 Engineering Senior Design Projects to Aid the Disabled, edited by John D. Enderle, NDSU Press, Fargo, North Dakota 58105

2. "NDSU Undergraduate Design Projects for the Disabled", L. S. Baczkowski, J. D. Enderle, D. J. Krause, J. L. Rawson, Biomedical Sciences Instrumentation, vol. 26, pp. 95-9, 1990

3. “Collaborative Learning in Engineering Design”, Sigrin Newell, Journal of College Science Teaching, vol. 19, no. 6, pp. 359-62, May 1990

4. "Bioengineering Practicum and Capstone Projects: A Cooperative of University, Industry, Hospital, and Government for the Physically Challenged", James V. Masi, Proceedings ASEE Middle Atlantic Section Fall 1997 Regional Conference, Session 7

5. "Interdisciplinary Miniprojects with Engineering and Occupational Therapy Students", H. G. Ansell, 1997 ASEE Annual Conference Proceedings, Session 1275 (CD ROM)

6. "Results of Client Based Freshman Design Projects", Melinda J. Piket-May, James P. Avery, ASEE/IEEE FIE 97 Conference Proceedings, http://fairway.ecn.purdue.edu/ fie/fie97/, Session F1F

7. Student projects at Rehab R\&D Center, http://guide.stanford.edu/Projects/StudentProj.html

8. NSF Engineering, http://www.eng.nsf.gov/, Bioengineering \& Environmental Systems, Biomedical Engineering, Biomedical Engineering/Research to Aid Persons with Disabilities

HENRY G. ANSELL received a Ph. D. (Electrophysics) from Polytechnic Institute of Brooklyn. He was employed for 25 years as an electrical engineer by AT\&T Bell Laboratories. Since fall 1987 he has been teaching at Penn State Berks Campus (now part of Penn State Berks-Lehigh Valley College). He can be reached at hga1@psu.edu for questions or comments. 